\title{
Aanbevelingen juristengroep uitvoering motie Dijksma
}

\author{
Olav Haazen, Femke Hendriks, Niels Lemmers, \\ Jurjen Lemstra, Daan Lunsingh Scbeurleeren \\ Brechjevan der Velden*
}

\section{Voorwoord}

Van 1 juli tot 15 oktober 2014 heeft een consultatie plaatsgevonden over een voorontwerp ter uitvoering van de motie Dijksma. Deze motie van de huidige staatssecretaris van Economische Zaken is met brede steun van de Tweede Kamer aangenomen en verzoekt de regering om de mogelijkheden van slachtoffers om collectief hun schade vergoed te krijgen te verbeteren door invoering van een collectieve schadevergoedingsactie.

Het beeld dat uit de consultatie naar voren kwam was dat er steun is voor de invoering van een collectieve schadevergoedingsactie als 'stok achter de deur'. Uit de consultatie is eveneens gebleken dat er behoefte is aan stroomlijning van de procedure, een verduidelijking van de regels inzake ontvankelijkheid van representatieve belangenorganisaties en een aanscherping van de regels voor de binding van gedupeerden.

Op 9 april 2015 heeft een stakeholderbijeenkomst plaatsgevonden over het Wetsvoorstel 'uitvoering motie Dijksma'. Tijdens deze stakeholderbijeenkomst is een discussiedocument besproken. In dit document waren discussiepunten opgenomen over onderwerpen die in de consultatie zijn gesignaleerd en waarop het voorontwerp verduidelijking behoeft. Uit de bijeenkomst kwam naar voren dat een aantal onderwerpen nog verder doordacht moet worden. Dit betreft in het bijzonder de vereenvoudiging van de voorgestelde procedure, de kwaliteit en ontvankelijkheid van representatieve belangenorganisaties en de finaliteit bij de afwikkeling van massaschades.

Naar aanleiding van deze bijeenkomst is, in overleg met de Minister van Veiligheid en Justitie, besloten in te gaan op het aanbod van enkele prakrijkjuristen van zowel verwerende als eisende zijde met veel ervaring op het terrein van massaclaims om samen met deze juristen (de 'juristengroep') de genoemde onderwerpen verder te doordenken.

* De 'Aanbevelingen juristengroep uitvoering motie Dijksma' (Den Haag, 7 december 2015) zijn gepubliceerd met toestemming van de auteurs.
In de periode juli tot en met oktober 2015 hebben deze zes juristen vier keer vergaderd in het bijzin van de betrokken wetgevingsjuristen van het Ministerie van Veiligheid en Justitie, Wynand Brants en Paulien van der Grinten. Het resultaat van hun werkzaamheden, die zij hebben verricht op persoonlijke titel, is neergelegd in de bijgevoegde aanbevelingen, die de wetgever richting moeten geven bij het opstellen van een aangepast wetsvoorstel voor de uitvoering van de motie Dijksma. De resultaten hiervan zijn op 3 november 2015 in de stakeholdersbijeenkomst besproken en bleken op breed draagvlak te mogen rekenen. Daarmee is de taak van de juristengroep afgerond en is de wetgever weer aan zet.

2 Nadere invulling toegangseisen en binding Uit de reacties op de consultatie over het voorontwerp en uit de stakeholderbijeenkomst van 9 april 2015 is naar voren gekomen dat het voorontwerp uitvoering motie Dijksma het doel van een effectieve en efficiënte afwikkeling van massazaken nog onvoldoende bereikt. Voor zowel gedaagden als gedupeerden biedt het voorontwerp nog niet de gewenste efficiëntiewinst.

Voor gedupeerden is van belang dat zij voldoende inzicht hebben in de werkwijze van een representatieve belangenorganisatie. $\mathrm{Zij}$ mogen niet het risico lopen dat voor hun belangen wordt opgekomen door organisaties die vooral vanuir eigen financieel of commercieel belang opereren, dan wel onvoldoende in staat zijn een langlopende, collectieve actie (financieel en kwalitatief) te dragen. Voor gedaagden is van belang dat zij kunnen inschatten of een representatieve belangenorganisatie daadwerkelijk representatief is voor de groep gedupeerden en voldoende in staat is een collectieve schadevergoedingsprocedure (financieel en kwalitatief) te dragen en daarom als gesprekspartner te dienen. De waarborgen in het voorontwerp om de kwaliteit van representatieve belangenorganisaties te garanderen moeten daartoe duidelijker en preciezer worden geformuleerd.

Daarnaast bestaat behoefte aan een mechanisme om verschillende collectieve acties, waaraan in voldoende mate gemeenschappelijke rechts- en feitelijke vragen aan ten grondslag lig- 
gen, te coördineren. Dit voorkomt dat een gedaagde zich geconfronteerd kan zien met meerdere - al dan niet gelijktijdige - collectieve procedures over dezelfde gemeenschappelijke rechts- en feitelijke vragen, zonder dat de gedaagde zicht heeft op een finale afwikkeling van het dossier. Ook is er een behoefte aan duidelijkheid over de vraag voor welke achterban een representatieve belangenorganisatie daadwerkelijk opkomt. Voor gedupeerden moet beter inzichtelijk worden welke representatieve belangenorganisatie het beste opkomt voor hun belangen.

Ook representatieve belangenorganisaties zelf hebben belang bij coördinatie van procedures en invoering van waarborgen voor de kwaliteit en transparantie van de verschillende representatieve belangenorganisaties. De bereidheid van de gedaagde tot afwikkeling van een massavordering via een schikking is groter als hij weet wie zijn gesprekspartner is en een schikking ook zoveel mogelijk finaliteit kan opleveren. Coördinatie voorkomt daarnaast dat representatieve belangenorganisaties door gedaagden tegen elkaar uitgespeeld kunnen worden.

Een betere kwaliteitswaarborging en coördinatie in collectieve procedures is bovendien in het belang van de rechterlijke macht. Dit geeft de mogelijkheid om procedures efficiënter af te wikkelen voor grotere groepen gedupeerden.

Kwaliteitswaarborgen en coördinatie kunnen worden bereikt door nadere regels in het wetsvoorstel op te nemen met betrekking tot de kwaliteit en de ontvankelijkheid van collectieve belangenorganisaties, alsmede met betrekking tot de mate waarin gedupeerden gebonden zijn aan een bepaalde uitspraak van de rechter (binding).

De aanbevelingen 1 tot en met 4 zijn erop gericht om dit doel te bereiken.

Efficiëntiewinst kan ook worden de behaald door de procedure anders en minder complex in te richten dan in het Voorontwerp is gebeurd. Aanbeveling 5 is hierop gericht. De juristengroep heeft zich in eerste instantie gefocust op de voorfase. Keuzes op dat punt zijn erop gericht om op veel van de in de reacties op het voorontwerp gesignaleerde problemen tegemoet te komen. Uitgangspunt bij aanbeveling 5 is dat voor het verdere verloop van de procedure zoveel mogelijk wordt aangeknoopt bij de gewone dagvaardingsprocedure, met een sterkere nadruk op het bereiken van een schikking.

Waar in de tekst gesproken wordt over een collectieve actie gaat het steeds om zowel een 'gewone' artikel 305a-actie als om een collectieve schadevergoedingsactie.

Aanbeveling I:

In het wetsvoorstel uitvoering motie Dijksma regelt de wetgever dat strenge eisen worden gesteld aan de ontvankelijkbeid van een representatieve belangenorganisatie in een collectieve actie of een collectieve schadevergoedingsactie.

\section{Ontwikkelingen vanaf de consultatie}

In de consultatie zijn er veel reacties gekomen op de eisen die zijn gesteld aan de ontvankelijkheid en kwaliteit van representatieve belangenorganisaties die een collectieve schadevergoedingsactie instellen. Er is brede kritiek op de formulering van de ontvankelijkheidseisen die te vaag en te algemeen zou zijn en daardoor niet goed toetsbaar door de rechter. Het voorontwerp zou volgens een aantal reacties te makkelijk toegang bieden tot de collectieve schadevergoedingsprocedure. Dit zou ertoe kunnen leiden dat representatieve belangenorganisaties warvan onduidelijk is in hoeverre de belangen van gedupeerden daadwerkelijk worden behartigd, toch toegang tot de procedure kunnen krijgen. Tegelijkertijd pleit een aantal reacties van partijen die in de regel opkomen voor gedupeerde partijen, ervoor de lat voor ontvankelijkheid niet té hoog te leggen. Daarbij is gewezen op de positieve resultaten die representatieve belangenorganisaties in het recente verleden hebben behaald voor gedupeerde consumenten. Ook is de vraag gesteld op welke wijze moet worden omgesprongen met representatieve belangenorganisaties waarvan tijdens de procedure blijkt dat zij later in de procedure alsnog niet voldoen aan de ontvankelijkheidseisen.

In de stakeholderbijeenkomst van 9 april 2015 is naar voren gekomen dat er in de praktijk behoefte is aan minder vage eisen ten aanzien van de ontvankelijkheid van representatieve belangenorganisaties in collectieve schadevergoedingsacties.

\section{Toelichting aanbeveling}

De juristengroep beveelt daarom aan in het wetsvoorstel duidelijkere eisen te stellen aan de kwaliteit en ontvankelijkheid van representatieve belangenorganisaties. Deze eisen zijn geïnspireerd op de Claimcode, waarvan belangrijke onderdelen in de jurisprudentie een plaats hebben verworven als toetssteen voor de ontvankelijkheid van representatieve belangenorganisaties en waarvan 'codificatie' langs onderstaande lijnen dient te worden uitgewerkt:

- Iedere representatieve belangenorganisatie moet aan dezelfde eisen voldoen voor ontvankelijkheid en het opkomen voor gedupeerden. Dit geldr in zowel een collectieve actie als een collectieve schadevergoedingsactie en ongeacht of de representatieve belangenorganisatie wordt aangewezen als Exclusieve Belangenbehartiger(zie aanbeveling 2).

- Iedere representatieve belangenorganisatie moet bij aanvang van de procedure gemotiveerd stellen dat en waarom zij aan de gestelde ontvankelijkheidseisen voldoet. De rechter toetst dit ambtshalve, nadat de gedaagde in de gelegenheid is gesteld zich dienaangaande uit te laten. Voor bestaande representatieve belangenorganisaties, zoals bijvoorbeeld de Consumentenbond en de VEB, geldt dat zij worden geacht ('presumptie') te voldoen aan de ontvankelijkheidscriteria voor Exclusieve Belangenbehartiger, voor zover deze ontvankelijkheidscriteria betrekking hebben op de kwaliteit van de belangenbehartiger. 
- Iedere representatieve belangenorganisatie moet, in ieder geval, aan de volgende eisen voldoen om ontvankelijk te zijn in een collectieve actie:

- Het moet gaan om een stichting of vereniging (zonder winstoogmerk) met volledige rechtsbevoegdheid die volgens haar statuten gelijksoortige belangen van andere personen behartigt. De bestuurders/oprichters mogen evenmin winstdoelstelling hebben die rechtstreeks of middellijk via de Stichting wordt gerealiseerd;

- De ingestelde rechtsvordering strekt tot bescherming van de (gelijksoortige) belangen die de stichting of vereniging volgens haar statuten behartigt;

- De representatieve belangenorganisatie moet voldoen aan eisen voor de kwaliteit van de organisatie. Deze eisen moeten betrekking hebben op:

- De governance van de organisatie: heeft de organisatie een goede structuur voor evenwichtige besluitvorming en verantwoording waarin de belangen van de gedupeerden voldoende zijn gewaarborgd?

- De financiering van de organisatie: is de organisatie in staat de kosten van een collectieve procedure voldoende te dragen en zijn de evt. van de achterban gevraagde bijdragen redelijk en proportioneel?

- De transparantie van de organisatie: ontbreekt elk tegenstrijdig belang en is de organisatie open over haar doelstellingen en werkwijzen?

- De juridische vertegenwoordiging van de organisatie: is een kwalitatief behoorlijke juridische vertegenwoordiging gewaarborgd?

- De ervaring (expertise) en herkenbaarheid ('track record') van de organisatie of de aan de organisatie verbonden bestuurders: wordt de organisatie herkend als spreekbuis van een bepaald belang?

- De toe- en uittreding van de achterban bij de organisatie: is er sprake van evenwichtige voorwaarden voor de aansluiting van individuele gedupeerden? Dit is relevant voor de beoordeling van de representativiteit.

- De representatieve belangenorganisatie maakt aannemelijk dat het voeren van deze collectieve actie efficiënter en effectiever is dan het instellen van een individuele vordering: Dit blijkt onder meer uit:

- De te beantwoorden feitelijke en rechtsvragen zijn in voldoende mate gemeenschappelijk.

- De representatieve belangenorganisatie beschikt over een achterban waarvan eenvoudig is vast te stellen dat deze bestaat uit een voldoende antal personen, die alleen dan wel gezamenlijk een voldoende groot financieel belang hebben.

- Bij de collectieve vordering blijkt niet summierlijk van de ondeugdelijkheid op het moment van indiening.
- De rechter let bij de keuze voor meest geschikte Exclusieve Belangenbehartiger bij uitstek op het trackrecord van een representatieve belangenorganisatie, wanneer zowel een ad hoc belangenorganisatie als een bestaande belangenorganisatie zich in een bepaalde vordering als Exclusieve Belangenbehartiger heeft aangemeld.

- De ontvankelijkheidseisen zijn doorlopende vereisten. Ook gaandeweg de procedure moet toetsbaar zijn of de representatieve belangenorganisatie hieraan voldoet. De juristengroep denkt hierbij bijvoorbeeld aan een rol voor een rechter-commissaris vergelijkbaar met de recent door de wetgever geïntroduceerde figuur van de raadsheercommissaris in de enquêteprocedure, die bij klachten of problemen ordenend op kan treden.

- Collectieve acties die alleen betrekking hebben op bepaalde ideële doelen ('algemeen belang-acties') en slechts een miniem financieel belang hebben, hoeven aan minder stringente eisen te voldoen.

\section{Aanbeveling 2:}

In bet wetsvoorstel uitvoering motie Dijksma regelt de wetgever dat de rechter in een collectieve actie de mogelijkheid krijgt een Exclusieve Belangenbehartiger aan te wijzen.

\section{Ontwikkelingen vanaf de consultatie}

In de consultatie is in verschillende reacties gepleit voor de introductie van een mechanisme waarbij één representatieve belangenorganisatie wordt aangewezen om de collectieve schadevergoedingsactie te voeren voor de hele groep van gedupeerden. Daarbij werd verwezen naar het lead plaintiff systeem, zoals het Amerikaans recht dat kent ${ }^{1}$. De rechter zou moeten kunnen selecteren welke organisatie het meest geëigend is om het voortouw te nemen bij de collectieve schadevergoedingsactie. Volgens sommigen zouden andere organisaties zich daarbij aan moeten kunnen sluiten.

Tijdens de stakeholderbijeenkomst van 9 april 2015 is hier langdurig over gesproken naar aanleiding van een notitie van Eumedion. Er bleek onder stakeholders een draagvlak was voor de introductie van een systeem waarbij één representatieve belangenorganisatie het voortouw krijgt om de collectieve schadevergoedingsactie te voeren. Voorwaarde voor de introductie was dat dit systeem zodanig kan worden ingericht dat het aansluit bij de bestaande Nederlandse systematiek waarin een representatieve belangenorganisatie opkomt voor de belangen van haar achterban.

1. Het Amerikaanse lead plaintiff systeem is overigens niet gebaseerd op een geselecteerde representatieve belangenorganisatie die opkomt voor de belangen van de groep gedupeerden, maar op een selectie van de gedupeerde die het meest aangewezen wordt geacht de procedure te voeren (meestal omdat die de grootste schade heeft geleden). Die gedupeerde krijgt dan de lead in de procedure en wordt daarmee de lead-plaintiff. 


\section{Toelichting aanbeveling}

De juristengroep adviseert de wetgever daarom om in het wetvoorstel een mechanisme op te nemen voor de aanwijzing van een Exclusieve Belangenbehartiger. Dit mechanisme zou aan de volgende voorwaarden moeten voldoen:

- Er wordt voorzien in de inrichting van een centraal register voor de registratie van collectieve acties, dat online te raadplegen is.

- Een collectieve actie op basis van artikel 3:305a BW kan bij iedere bevoegde rechtbank worden aangebracht. De rechtbank waar de zaak is aangebracht registreert deze collectieve actie vervolgens in het centrale register met de volgende informatie: (a) een summiere omschrijving van de collectieve actie, de feitelijke stellingen waarop deze is gebaseerd en of de actie een vordering strekt tot schadevergoeding, verbod, gebod, verklaring voor recht of anderszins, (b) de partijen, (c) een zo nauwkeurig mogelijke omschrijving van het collectief van belanghebbenden in wier belang de vorderingen zijn ingesteld en (d) een link naar een kosteloos te downloaden uittreksel van de dagvaarding.

- De rechtbank waar de collecrieve actie is aangebracht verricht geen proceshandelingen totdat een voorgeschreven termijn verstreken is.

- Binnen de voorgeschreven termijn kunnen eventuele andere representatieve belangenorganisaties die opkomen voor gelijksoortige belangen zich melden bij een daartoe aangewezen rechtbank met het verzoek als Exclusieve Belangenbehartiger te worden aangewezen voor de collectieve actie of collectieve schadevergoedingsactie. Voorwaarde is dat zij daarbij ook hun collectieve vordering formuleren die betrekking heeft op dezelfde rechtsvragen en feitelijke vragen en deze onderbouwen. Wanneer meerdere collectieve acties worden of zijn aangebracht die betrekking hebben op gelijksoortige gemeenschappelijke rechtsen feitelijke vragen, worden de zaken verwezen naar een daartoe aangewezen rechtbank.

- Als geen andere representatieve belangenorganisaties zich melden, kan de collectieve actie bij de oorspronkelijke rechrbank worden afgewikkeld.

- De daartoe aangewezen rechtbank wijst uit de representatieve belangenorganisaties die zich hebben gemeld om als Exclusieve Belangenbehartiger te worden aangemerkt, een Exclusieve Belangenbehartiger aan. Voorwaarden voor selectie als Exclusieve Belangenbehartiger zijn:

- De representatieve belangenorganisatie voldoet aan de eisen voor ontvankelijkheid;

- De representatieve belangenorganisatie wordt het meest geschikt geacht tot het opkomen voor de groep, gezien:

- haar omvang van de achterban (aantal gedupeerden)

- de grootte van het door haar vertegenwoordigde financiële belang

- andere werkzaamheden voor de gedupeerden voor wie zij opkomt in of buiten rechte
- haar track record.

- De rechtbank beoordeelt daarnaast of de zaak als collectieve actie kan worden afgewikkeld, waarop de collectieve actie precies ziet en voor welke nauw omschreven groep gedupeerden deze collectieve schadevergoedingsactie wordt gevoerd.

- De representatieve belangenorganisatic die als Exclusieve Belangenbehartiger wordt aangewezen, krijgt daarmee het recht en de verantwoordelijkheid om exclusief te procederen in een collectieve actie. Tegen deze beslissing staat geen hoger beroep open.

- Iedere representatieve belangenorganisatie, ook een ad hoc organisatie, kan kwalificeren als Exclusieve Belangenbehartiger.

- Als de aard van de collectieve actie of van de representatieve belangenorganisaties of de daarin behartigde belangen daartoe aanleiding geven kan de rechter ervoor kiezen om meerdere (co- of sub-) Exclusieve Belangenbehartigers in een collectieve actie aan te wijzen, bijvoorbeeld om bepaalde deelbelangen te vertegenwoordigen.

- Indien en voor zover de aard van de collectieve actie of van de representatieve belangenorganisaties of de daarin behartigde belangen daartoe aanleiding geven kan de rechter representatieve belangenorganisaties die niet als Exclusieve Belangenbehartiger worden aangewezen, in de gelegenheid stellen te worden gehoord in de inhoudelijke procedure over de collectieve vordering.

- De daartoe aangewezen rechtbank kan de zaak afdoen op een andere locatie, als de aard van de collectieve actie daartoe aanleiding geeft, bijvoorbeeld vanwege het regionale karakter ervan.

- Voor kort geding kunnen afwijkende termijnen en bepalingen gelden.

Aanbeveling 3:

In het wetsvoorstel uitvoering motie Dijksma regelt de wetgever dat er nadere eisen worden gesteld aan de binding van gedupeerden, zodat een gedaagde niet onevenredig wordt belast met een veelheid aan individuele en collectieve procedures over. dezelfde schadeveroorzakende gebeurtenis en gedupeerden een duidelijk keuzemoment bebben om al dan niet mee te doen aan de collectieve actie.

\section{Ontwikkelingen vanaf de consultatie}

In de consultatie en tijdens de stakeholderbijeenkomst is eveneens naar voren gekomen dat er behoefte is aan regels voor de binding van gedupeerden. Veel opmerkingen in de consultatie gaan over de wijze van binding van gedupeerden aan de procedure en het resultaat ervan en over de wenselijkheid van finaliteit. Veel respondenten wensen een eerder tijdstip van binding van gedupeerden, liefst aan het begin van de procedure. Daarbij wijzen de reacties ook op de Europese Aanbeveling voor collectief verhaal uit 2013 waarin de Europese Commissie een voorkeur uitspreekt voor opt in vooraf boven opt out. Daarnaast wensen sommigen de mogelijkheid dat de uitkomst van de procedure bindend is voor alle gedupeerden om meer finali- 
teit te bereiken en free riders zoveel mogelijk te voorkomen. Ook is geopperd dat de rechter het resultaat zelf op basis van de WCAM (maar zonder een verzoek daartoe en zonder betrokkenheid van het gerechtshof Amsterdam) verbindend kan verklaren voor alle gedupeerden. De mogelijkheid voor de rechter om gedupeerden voor wie de verzoeker opkomt, zich ter griffie te laten melden alvorens een schaderegeling op te leggen (artikel 1018g lid $6 \mathrm{Rv}$ ), achten sommigen (veel) te laat. Anderen achten deze mogelijkheid niet in het belang van gedupeerden en daarom niet wenselijk. Een enkeling wil juist dat gedupeerden zich pas op basis van het eindresultaat uitspreken over de vraag of zij gebonden willen zijn. De mogelijkheid dat niet per se voor alle gedupeerden van een bepaalde gebeurtenis maar slechts voor een beperkte groep wordt opgekomen en dat de procedure en het resultaat zich tot die groep beperken, lijkt door de meeste reacties wenselijk te worden geacht.

Tijdens de stakeholderbijeenkomst van 9 april 2015 bleek er draagvlak te zijn om de binding van gedupeerden aan een uitspraak van de rechter duidelijker te regelen dan nu en in het voorontwerp het geval is. Op dit moment heeft een uitspraak van artikel 3:305a BW tussen collectieve representatieve belangenorganisatie en een gedaagde slechts precedentwerking voor gedupeerden.

\section{Toelichting aanbeveling}

Daarom adviseert de juristengroep de wetgever om duidelijkheid te verschaffen over de groep gedupeerden die door een bepaalde Exclusieve Belangenbehartiger in een collectieve actie worden vertegenwoordigd. Op deze manier worden gedaagden niet onevenredig belast met individuele procedures die betrekking hebben op gelijksoortige rechts- en feitelijke vragen als in lopende collectieve procedures, waarin een Exclusieve Belangenbehartiger is aangewezen. De door de juristengroep voorgestelde structuur behelst een keuze voor het opt-out systeem om redenen van het kunnen bereiken van binding van gedupeerden en het bereiken van finaliteit.

Daarbij gelden de volgende voorwaarden:

- De Exclusieve Belangenbehartiger wordt geacht voor de gehele groep gedupeerden in een collectieve procedure op te komen.

- Individuele gedupeerden kunnen binnen een bepaalde termijn voor de aanvang van de inhoudelijke procedure besluiten van deelname aan de collectieve procedure af te zien (opt-out). Aan de opt out verklaring kunnen nadere voorwaarden worden gesteld mits deze niet onnodig bezwarend voor de gedupeerde zijn. De rechtbank die de Exclusieve Belangenbehartiger anwijst stelt hiervoor een termijn en bepaalt de wijze van bekendmaking, waaronder in elk geval via het eerder genoemde centrale register. Collectieve opt out is niet mogelijk.

- Eventuele collectieve acties die aanhangig worden gemaakt na het aanhangig worden van een collectieve actie over hetzelfde onderwerp maar voordat de 90-dagen termijn voor het melden als Exclusieve Belangenbehartiger is aangevangen, worden van rechtswege gevoegd met de als eerste aanhangig gemaakte collectieve actie.

- Representatieve belangenorganisaties die niet tot Exclusieve Belanghartiger zijn benoemd kunnen geen parallelle art. 305a collectieve actie starten voor gedupeerden die gebruik hebben gemaakt van hun opt-out recht. Wel houden zij die hebben ge-opt-out de mogelijkheid om een individuele procedure te starten of te procederen op basis van volmacht.

- De uitspraak van een rechter is bindend voor de gedupeerden in een collectieve (schade-)vergoedingsactie, tenzij zij van deelname in de procedure hebben afgezien door een opt out verklaring die aan nadere voorwaarden moet voldoen.

- Bereiken partijen een schikking dan wordt deze ter goedkeuring aan de rechter voorgelegd. Gedupeerden die niet hebben ge-opt-out aan het begin van de procedure, hebben de mogelijkheid hun bezwaren tegen de schikking schriftelijk binnen een bepaalde door de rechter te bepalen termijn kenbaar te maken aan de rechter. Verklaart de rechter de schikking verbindend, dan hebben gedupeerden vervolgens de mogelijkheid zich aan de binding daarvan de onttrekken door een opt out verklaring. De schikking kan nadere eisen bevatten waaraan deze opt out verklaring moet voldoen, zoals opgave van de omvang van de vordering van de gedupeerde.

- Onttrekking aan een goedgekeurde schikking door de gedaagde is alleen mogelijk indien de schikking daarin voorziet en uitsluitend op de grond dat het aantal gedupeerden dat opt out of het gevorderde bedrag dat zij vertegenwoordigen, een vooraf vastgestelde grens overschrijdt, waardoor de schikking voor te weinig gedupeerden of anderszins onvoldoende gevolgen heeft.

- De collectieve schadevergoedingsactie waarin een Exclusieve Belangenbehartiger is aangewezen, heeft voorrang op individuele procedures of procedures op basis van volmacht die betrekking hebben op gelijksoortige rechts- en feitelijke vragen.

Dit kan worden geregeld, door de volgende voorwaarden in het wetsvoorstel op te nemen:

- Indien daartoe aanleiding bestaat, kan de rechter op verzoek van de meest gerede partij in een individuele procedure die later wordt aangebracht en die betrekking heeft op gelijksoortige rechts- en feitelijke vragen schorsen. Een individuele partij kan een verzoek tot opheffing van de schorsing doen indien de schorsing langer heeft geduurd dan 12 maanden.

- De Exclusieve Belangenbehartiger kan de verjaring van vorderingen van individuele gedupeerden ten behoeve van hen stuiten.

- Voor individuele gedupeerden die binnen de daarvoor door de rechter gestelde termijn na benoeming van de Exclusieve Belangenbehartiger hebben ge-opt-out, heeft de collectieve stuiting niet langer effect. Zij dienen indivi- 
dueel hetzij in hun opt out verklaring hetzij los daarvan een stuitingshandeling te verrichten.

\section{Aanbeveling 4: \\ In het wetsvoorstel uitvoering motie Dijksma regelt de wetge- ver dat een effectieve scope rule wordt opgenomen die verenig- baar is met het internationale bevoegdheidsrecht en bet Europese recht.}

\section{Ontwikkelingen vanaf de consultatie}

Tijdens de consultatie is er ook de nodige kritiek geuit op de voorgestelde scope rule. Volgens de meeste reacties was een scope rule wel wenselijk, maar was het voorgestelde regime niet effectief genoeg. Een minderheid gaf aan dat de scope rule niet te beperkend mocht zijn. Ten slotte zijn er vragen gesteld over de Europeesrechtelijke houdbaarheid van een scope rule.

\section{Toelichting juristengroep}

Een collectieve schadevergoedingsactie die niet beperkt is tot een bepaald rechtsgebied (bijvoorbeeld beleggingsvorderingen) is een toevoeging aan het Nederlandse arsenaal voor het collectief afwikkelen van vorderingen. De motie Dijksma is erop gericht deze toevoeging te doen ter verbetering van het collectief schadeverhaal door consumenten. Doel van een scope rule is om deze toevoeging beschikbaar te maken voor zaken met een voldoende nauwe band met Nederland. Een scope rule moet voorkomen dat een Nederlandse collectieve schadevergoedingsactie kan worden gebruikt voor zaken waarin de Nederlandse rechter wel rechtsmacht heeft maar er feitelijk geen of onvoldoende nauwe band bestaat tussen de collectieve vordering en de Nederlandse rechtssfeer. De enkele oprichting van een Nederlandse stichting is bijvoorbeeld onvoldoende aanknoping met Nederland als deze stichting opkomt voor uitsluitend buitenlandse gedupeerden en er geen andere aanknopingspunten met Nederland zijn.

Over de vormgeving van een scope rule wordt verschillend gedacht. De juristengroep adviseert de wetgever in het wetsvoorstel een evenwichtige scope rule op te nemen met inachtneming van de internationale bevoegdheidsregels en Europeesrechtelijke bepalingen.

\section{Aanbeveling 5:}

In het wetsvoorstel uitvoering motie Dijksma regelt de wetgever dat de collectieve schadevergoedingsprocedure aanzienlijk wordt versimpeld ten opzicht van het voorontwerp.

\section{Ontwikkelingen vanaf de consultatie}

De wijze waarop de collectieve schadevergoedingsactie in het voorontwerp is vormgegeven heeft de nodige, kritische, reacties opgeroepen. Vrijwel alle reacties vinden de procedure zoals beschreven in het voorstel (te) ingewikkeld. Veel reacties menen dat het voorontwerp op dit punt niet is geslaagd. $\mathrm{Zij}$ menen dat de procedure teveel stappen heeft en daardoor te stroperig wordt. Dit brengt een efficiënte afwikkeling in gevaar. Ook missen sommigen een duidelijke beslisboom voor de rechter over alle aspecten (causaliteit, eigen schuld, omvangschade) van de massaschade, hoewel de mogelijkheid tot het vragen van deelbeslissingen hierin op zichzelf wel voorziet. Veel reacties suggereren dat de procedure eenvoudiger kan door stappen te schrappen.

Ook de keuze voor de verzoekschriftprocedure stuit op kritiek. Sommige partijen achten een collectieve schadevergoedingsactie bij uitstek een vorderingsprocedure en vinden de voordelen van de verzoekschriftprocedure (ruimere regiemogelijkheden voor de rechter) niet opwegen tegen de nadelen. Het ontbreken van de mogelijkheid tot vrijwaring wordt daarbij expliciet als bezwaar genoemd. Daarnaast is er bezwaar tegen de keuze om geen rechtsmiddel open te stellen tegen de uiteindelijke vaststelling van een regeling voor de afwikkeling van massaschade. Veel respondenten menen dat deze beslissing van de rechter zo belangrijk is dat hiertegen beroep moet open staan.

Ten slotte is er in de consultatie op gewezen dat de rol van de rechter in de procedure onduidelijk is. Een aantal reacties merkt op dat het voor de rechter heel lastig zal zijn een collectieve schadevergoedingsregeling vast te stellen en dat onduidelijk is op basis van welke normering hij dit moet doen en wat het karakter ervan is (opgelegde schikking of rechterlijk oordeel). Sommige reacties vragen zich af of de rechter wel geschikt is om enerzijds de rol te spelen van procesbegeleider in het bereiken van een schikking en anderzijds de rol van beslisser. Ook vragen sommigen zich af of de rechter wel beschikt over voldoende relevante informatie om een regeling voor een collectieve schadevergoeding vast te kunnen stellen, gezien het complexe karakter van een collectieve schadeafwikkeling en de betrokkenheid van derden (zoals verzekeraars) bij dit proces. Sommige reacties stellen de vraag of de rechter een regeling vaststelt/zou moeten vaststellen die vooral gebaseerd is op een redelijkheidstoets voor wat betreft de hoogte van de aan gedupeerden per categorie toegekende vergoeding of dat de rechter een volledige juridische vaststelling van de omvang van de schade en toekenning van schadevergoeding per categorie doet/zou moeten doen. Ten slotte vragen sommigen zich af of de schadeafwikkeling zelf niet onder regie van bijvoorbeeld een rechter-commissaris zou moeten plaatsvinden.

\section{Toelichting aanbeveling juristengroep}

De juristengroep beveelt aan dat de procedure voor een collectieve actie een dagvaardingsprocedure blijft, ook als de collectieve actie een vordering tot schadevergoeding betreft. Nadat de rechter een Exclusieve Belangenbehartiger heeft aangewezen, stelt de rechter een termijn aan partijen voor het beproeven van een schikking en de eventuele aanpassing van de oorspronkelijke dagvaarding in het licht van de gemaakte opmerkingen tijdens de benoemingsprocedure. Wordt binnen de gestelde termijn geen schikking bereikt, dan krijgt de gedaagde de gelegenheid inhoudelijk op de collectieve vordering te reageren (conclusie van antwoord). De gewone procesregels gelden, inclusief de regels voor al dan niet tussentijds hoger 


\section{Maandblad}

Ondernemingsrecht

beroep̀ van een tussenuitspraak. Betreft de procedure een collectieve schadevergoedingsactie, dan kan de rechter in iedere stand van de procedure in een tussenvonnis de Exclusieve Belangenbehartiger bevelen de schade van de benadeelden nader te onderbouwen of te classificeren in schadeklassen.

De eventuele veroordeling tot schadevergoeding geschiedt in de vorm van een condemnatoir tussenvonnis dat tevens gedeeltelijk eindvonnis is. De gedaagde wordt daarbij veroordeeld om aan iedere gedupeerde (of als er klassen zijn gedefinieerd: iedere gedupeerde per klasse aan wie schadevergoeding wordt toegekend) die niet heeft ge-opt-out de schadevergoeding te voldoen conform de berekeningswijze die in het vonnis is neergelegd. Benadeelden moeten zich daartoe binnen een door de rechter te bepalen termijn bij gedaagde of bij een andere in het vonnis vermelde instantie melden door middel van een nader te bepalen formulier. De gedaagde moet binnen drie maanden van dit vonnis in hoger beroep indien hij deze veroordeling in appel aan de orde wil stellen. Het vonnis kan niet uitvoerbaar bij voorraad worden verklaard; het instellen van appel schorst derhalve altijd de executie. De reden hiervoor is dat de gedaagde anders voor een te groot restitutierisico wordt geplaatst. De reden dat de veroordeling niet bij eindvonnis geschiedt, is dat het nuttig is om de rechter en/of de r-c nog een toezichthoudende rol te laten houden gedurende de periode waarin de veroordeelde gedaagde het vonnis nakomt of om executiegeschillen te beslechten. Benadrukt zij dat het aan partijen is om de afwikkeling van de veroordeling vorm te geven en uit te voeren; niet beoogd wordt hier een uitvoerende taak bij de rechter neer te leggen. Het eindvonnis wordt vervolgens gewezen nadat de veroordeling is afgewikkeld.

Bereiken partijen gedurende de procedure een collectieve schikking, dan kan de rechtbank deze schikking verbindend verklaren overeenkomstig de regeling in de WCAM, waarbij bepaalde formele vereisten kunnen worden geschrapt nu deze al zijn vervuld in een eerdere fase van de procedure. 